DOI: http://dx.doi.org/10.18764/2358-4319.v10n3p130-153

\title{
Revisitando as políticas de formação de professores no Brasil (1827-1930)
}

\author{
Lucas Gabriel Franco Gomez \\ Lilian Maria Paes de Carvalho Ramos ${ }^{2}$
}

\section{RESUMO}

Este artigo apresenta parte do resultado final da dissertação de mestrado defendida em maio de 2017 no PPGEduc/UFRRJ. Consiste em uma retomada histórica das políticas de formação docente no período de 1827 a 1930, através de revisão bibliográfica e análise documental, destacando concepções, tensões e desafios que as caracterizaram. Partimos da constatação de que no século XIX, o problema da instrução nacional forjou as bases para a constituição de políticas de formação docente, tendo em vista que sem professores devidamente qualificados não seria possível garantir o funcionamento das escolas elementares. Foram desenvolvidos diversos ensaios em âmbito nacional e nas unidades federativas, que compreenderam: sistemas de indicação dos professores, escolhas através de conselhos e comissões, exames e concursos de admissão, instalação de escolas normais e adoção do regime de professores adjuntos. Entretanto, consideramos que muitas análises produzidas sobre a área foram e são marcadas pela superficialidade, desconsiderando as discussões já existentes, o que resulta em conclusões pessoais e descontextualizadas. Concluímos que com pequenos avanços e muitas críticas, a questão da formação docente paulatinamente conquistou espaço na agenda política e configurou um quadro de entraves e ranços históricos herdados pelas atuais políticas de formação. Contudo, acreditamos que enquanto a questão da valorização, da formação e da qualificação docente não constituírem uma pauta urgente na sociedade, não será possível encontrar caminhos de mudança no cenário educacional com uma proposta consistente, abrangente e atualizada.

1 Mestreem Educação pela Universidade Federal Rural do Rio de Janeiro.E-mail: lucas30stm22@ gmail.com

2 Doutora em Educação pela Universidade Estadual de Campinas. Professora do Departamento de Educação e Sociedade do Instituto Multidisciplinar/UFRRJ.. E-mail: lilianmpcramos@ yahoo.com.br 
Palavras-chave: Formação docente, Políticas Educacionais, Qualificação, Valorização Docente.

\section{Revisiting the teacher training policies in Brazil (1827-1930)}

\section{ABSTRACT}

This article presents part of the result of the master dissertation concluded in May 2017 at PPGEduc/UFRRJ. It consists of a historical resumption of teacher education policies from 1827 to 1930 , through bibliographical review and documentary analysis, highlighting the conceptions, tensions and challenges that characterized them. In the nineteenth century, the problem of national education laid the foundations for the constitution of teacher education policies, since without proper teachers it would not be possible to guarantee the functioning of elementary schools. Many national and federal trials were developed, including teacher nomination systems, appointment by boards and commissions, examinations and admission contests, creation of regular schools, and adoption of the adjunct teacher regime. We conclude that with small advances and many criticisms, the issue of teacher training has gradually gained space in the political agenda and has configured a framework of historical obstacles and ranks inherited by the current training policies. However, we consider that many analyzes produced lately in this area are superficial and, therefore, disregard the existing discussions and result in personal and decontextualized conclusions. Moreover, we are convinced that if the issue of teacher appreciation, training and qualification does not become an urgent agenda in society, it will not be possible to find ways to change the educational landscape with a consistent, comprehensive and up-to-date proposal.

Keywords Teacher training, Educational Policies, Qualification, Teacher Valorization.

Revisando las políticas de formación de profesores en Brasil (1827-1930)

\section{RESUMEN}

Este artículo presenta parte del resultado de la disertación de maestría defendida en mayo de 2017 en el PPGEduc /UFRRJ. Consiste en una 
reanudación histórica de las políticas de formación docente en el período de 1827 a 1930, a través de revisión bibliográfica y análisis documental, destacando concepciones, tensiones y desafíos que las caracterizaron. En el siglo XIX, el problema de la instrucción nacional forjó las bases para la constitución de políticas de formación docente, teniendo en cuenta que sin profesores debidamente cualificados no sería posible garantizar el funcionamiento de las escuelas elementales. Se desarrollaron diversos ensayos a nivel nacional y en las unidades federativas que comprendieron sistemas de indicación de los profesores, elecciones a través de consejos y comisiones, exámenes y concursos de admisión, instalación de escuelas normales y adopción del régimen de profesores adjuntos. Concluimos que con pequeños avances y muchas críticas, la cuestión de la formación docente paulatinamente conquistó espacio en la agenda política y configuró un cuadro de obstáculos y rangos históricos heredados por las actuales políticas de formación. Pero también consideramos que muchos análisis producidos últimamente en esta área son hechos de modo superficial y, por eso, desconsideran las discusiones ya existentes, lo que resulta en conclusiones personales y descontextualizadas. Además, creemos que mientras la cuestión de la valorización, la formación y la cualificación docente no constituyen una pauta urgente en la sociedad, no será posible encontrar caminos de cambio en el escenario educativo con una propuesta consistente, exhaustiva y actualizada.

Palabras clave: Formación Docente, Políticas Educacionales, Calificación, Valorización Docente.

\section{Introdução}

Este artigo apresenta parte do resultado final da dissertação de mestrado apresentada em maio de 2017 ao Programa de Pós-Graduação em Educação, Contextos Contemporâneos e Demandas Populares (PPGEduc), da Universidade Federal Rural do Rio de Janeiro, sobre políticas de formação docente. Nele realizamos um resgate histórico das políticas de formação de professores no Brasil, por meio de pesquisa bibliográfica e análise documental, na tentativa de caracterizá-las e verificar seus fundamentos, concepções, limites e desafios, salientando como a formação e a qualificação docente foram nelas retratadas.

O estudo da história destas políticas foi feito a partir da busca pelos dispositivos legais, os quais foram analisados e cotejados em 
busca de inovações. Para esta tarefa, realizamos uma adaptação da sistematização temporal proposta por Saviani (2009), abrangendo os três primeiros períodos por ele apontados, que vão da Lei de Escolas de Primeiras Letras em 1827 até 1930. A seleção deste período específico se justifica por sua importância para a formação docente no Brasil, pois nele surgiram formas de seleção como os exames e os concursos e foram criadas as escolas normais, além de ter sido adotado o regime de professores adjuntos.

Foram selecionados alguns estados onde foram criadas escolas normais para retratar o contexto da época e a forma como os professores eram preparados, pois as iniciativas desencadeadas em outras unidades federativas não se diferenciaram muito das escolhidas para esta análise.

A importância em revisitar estas políticas se deve ao fato de que elas representam o marco histórico inicial e as tentativas de regulamentar a formação docente no Brasil como um todo e em alguns Estados em particular. Os pequenos avanços e os numerosos dilemas enfrentados na atualidade tiveram origem nestas iniciativas do passado que, por não se consolidarem, contribuíram para um cenário de descontinuidade política na área.

\section{Políticas de formação docente de 1827 A 1930}

\section{A Lei das Escolas de Primeiras Letras e o Ato Adicional de 1834}

A presença da formação docente na legislação educacional brasileira se deu lentamente, à medida que o Poder Público percebeu não só sua importância na vida em sociedade, mas também o impacto desta ação na construção e desenvolvimento da nação.

A chegada da família real portuguesa ao Brasil, em 1808, devido à invasão napoleônica, trouxe como consequência várias mudanças políticas, sociais e educacionais, ainda que incipientes. $O$ estabelecimento do Governo Português no Brasil e a expansão da Colônia forjaram as demandas por instituições educativas, pois era necessário formar pelo menos aqueles que trabalhariam para garantir o funcionamento dos serviços criados.

A educação básica não foi alvo de atenção neste período e os esforços se voltaram para criação dos cursos de Medicina, Cirurgia, Agricultura, Cursos Militares e para formação dos funcionários do Estado. No 
primeiro Curso de Medicina e Cirurgia na Bahia,os professores eram escolhidos pelo cirurgião-mor, devendo dar aulas práticas e teóricas. No Rio de Janeiro foi designado o cirurgião-mor para ser professor de Anatomia e os professores eram escolhidos ou pela aferição da sua capacidade e conduta moral, ou por indicação. Apesar da criação de escolas de primeiras letras em várias províncias, podemos afirmar não ter havido alterações significativas em relação ao trabalho docente no período pombalino, quando os professores em geral eram mal pagos, mal preparados, escolhidos para ocuparem os cargos por indicação e não havia formação oficial pública.

Um dos importantes dispositivos legais sobre formação do Primeiro Reinado (período que se seguiu à Proclamação da Independência em 1822 e foi marcado pelo desequilíbrio social, econômico e político), que obteve expressividade por ser a primeira lei que melhor caracterizou a educação pública, foi a Lei das Escolas de Primeiras Letras, de 15 de outubro de 1827. Esta lei imperial expressou a preocupação com a educação da população, sendo vista mais tarde como uma tentativa ainda muito frágil e que não levou em conta as previsões orçamentárias e estruturais para efetivar as transformações oriundas do seu cumprimento. Ela previu no artigo $1^{\circ}$ que "em todas as cidades, villas e logares mais populosos, haverão as escolas de primeiras letras que forem necessárias" (BRASIL, 1827). Além de inexistir dotação orçamentária para tal, a maior parte dos artigos relacionados à educação dizia respeito apenas à educação dos herdeiros do trono.

Em relação à formação docente, a referida lei estabeleceu o salário dos professores, que eram definidos pelos presidentes das províncias em Conselho, considerando as circunstâncias da população e o custo dos lugares onde aconteciam as aulas (art. $3^{\circ}$ ). $\mathrm{O}$ artigo $5^{\circ}$ determinou que os "[...] professores, que não tiverem a necessária instrucção deste ensino, irão instruir-se em curto prazo e à custa dos seus ordenados nas escolas das capitaes" (BRASIL, 1827).

Os professores eram formados no método do ensino mútuo, que teve origem na Inglaterra e era baseado no monitoramento. Deveriam se preparar em um curto período de tempo nas escolas das capitais e pagar suas despesas com o salário que recebiam. Já os artigos $7^{\circ}$ e $8^{\circ}$ estipularam um exame de admissão pública para aqueles que pretendessem ocupar as cadeiras: os candidatos tinham que estar em gozo dos direitos civis e políticos, ter uma boa conduta e serem considerados os 
mais dignos dentre os pretendentes. Eram avaliados publicamente perante os presidentes das províncias em Conselho.

De acordo com o artigo 10,os professores com mais de 12 anos de exercício sem interrupção, que tivessem sido prudentes, cuidadosos, atenciosos em seu trabalho, com grande número e aproveitamento dos alunos, poderiam receber uma gratificação anual que não excedesse a $1 / 3$ do seu salário. Os presidentes, em Conselho, estavam autorizados, mas não obrigados, a concederem gratificações, só que a lei não especificou por quanto tempo permaneceria o benefício. Este prêmio compunha uma espécie de plano de carreira. Já o artigo 12 estabeleceu que as professoras fossem escolhidas pelo mesmo exame dos professores (regulamentado no $\operatorname{art.70}$ ), sendo selecionadas as candidatas que tivessem mais conhecimento e se saíssem melhor no exame.

O Ato Adicional de 1834 alterou a Constituição do Império, passando a responsabilidade pela educação primária para as províncias e deixando sob sua responsabilidade a criação, a supressão e o estabelecimento dos salários e empregos provinciais, como afirma Saviani (2009). As Faculdades de Medicina, Cursos Jurídicos e Academias seriam regulamentadas por lei geral. Esta mudança fez com que as províncias tendessem a adotar modelos europeus de criação das escolas normais para formação dos professores de primeiras letras.

A criação das Escolas Normais: Rio de Janeiro, Mato Grosso, Bahia e São Paulo.

O movimento das escolas normais foi impulsionado pela preocupação com a educação que surgiu após a Revolução Francesa, pois era necessária a existência de estabelecimentos que garantissem a preparação dos responsáveis pela instrução do povo. A escola normal laica surgiu, como relata Schaffrath (2008), após a Revolução Burguesa na França. Esta, mesmo com vida breve, constituiu uma concepção de formação eminentemente científica, com programas densos, complexos e orientados para a pesquisa científica.

Dois fatores principais contribuíram para a criação destas escolas na França: uma lei de 1794 sobre o ensino obrigatório de língua francesa nos lugares onde era falado o dialeto e o aumento do número de alunos em busca de formação. Inspirada na tentativa alemã, onde já se buscava a constituição de normas para a formação, a escola normal 
francesa (SCHAFFRATH, 2008) estava ligada à ideia de ensino obrigatório e empenhada na construção de normas que servissem para regulamentar a profissão de professor. Para frequentar esta escola era preciso ter entre 16 e 25 anos, ter boa conduta, estar vacinado contra varíola e não possuir doença que impedisse o exercício da profissão. Igualmente, para ingressar na escola normal, o candidato fazia uma prova oral e uma escrita que serviam para verificar seus conhecimentos e saber sua religião. Os cursos duravam dois ou três anos e incluíam práticas pedagógicas em escolas primárias, que funcionavam nos prédios anexos às escolas normais.

O modelo de formação de professores das escolas do Brasil a partir do séc. XIX foi adotado seguindo uma tendência presente em vários países europeus, observando a capacidade da escola de conformar o pensamento e a consciência dos cidadãos em torno da ideia da consolidação do Estado. Por este modelo, a educação passa a ser vista como possibilidade de uniformizar a formação. Mais tarde, a importância da figura feminina como primeira educadora na família, principalmente no aspecto moral, ganha bastante destaque, tanto que o número de muIheres durante muito tempo foi superior ao de homens no magistério.

Os governantes viram na formação a possibilidade de forjar uma mentalidade nacional em que predominava o pensamento e o projeto das elites, pois a educação também era vista como base para o progresso. O modelo das escolas normais se expandiu pelo Brasil de forma significativa, permanecendo até os dias atuais. A seguir, serão destacados dispositivos legais que autorizaram e regulamentaram a criação de algumas escolas normais, pois ainda que não existisse uma política de formação docente mais específica e delineada, estas leis oferecem pistas para compreensão do período histórico.

A primeira escola normal no Brasil foi criada em 1835, na Província do Rio de Janeiro e ficou conhecida como a Escola Normal de Niterói. Esta escola seguia uma proposta das elites, pela qual, mais do que alfabetizar os cidadãos, as escolas deveriam ensinar e inculcar valores morais, de modo que os professores formados nestas escolas seriam mais mestres de moralidade do que alguém que transmitia conhecimentos. Isto também se expressava nos critérios de admissão dos candidatos ao magistério, já que eram privilegiados os aspectos de conduta sobre o conhecimento na área. De acordo com Schaffrath (2008), o fato de já existir no Rio de Janeiro uma escola de ensino secundário e outras aulas 
separadas contribuiu para que a Província fosse pioneira na implantação das escolas normais.

O Decreto n¹0, de 10 de abril de 1835, que dispôs sobre a criação da Escola Normal na capital da Província do Rio de Janeiro (Niterói), no artigo $1^{\circ}$ estabeleceu que esta escola serviria para habilitar os candidatos ao magistério de instrução primária e os professores que não tivessem se formado de acordo com a Lei das Escolas de Primeiras Letras. $O$ valor do ordenado foi fixado em um conto e seiscentos mil réis e também foi garantida a possibilidade da concessão pelo presidente da Província de uma gratificação de até quatrocentos mil réis anuais, segundo critérios de merecimento pela aptidão profissional e pelo número de alunos com aproveitamento (artigo $2^{\circ}$ ).

A forma de ingresso foi definida no artigo 4: para ser admitida a matrícula na Escola Normal requeria-se ser cidadão brasileiro, maior de dezoito anos, com bons antecedentes morais e saber ler e escrever. Além dos requisitos enunciados, os candidatos deveriam fazer um requerimento para o Presidente da Província, junto com um atestado de boa conduta concedido pelo juiz de paz da sua região; só então passariam por um exame para testar seus conhecimentos de leitura e escrita (art. $6^{\circ}$ ). Existiam também bolsas para quem não podia pagar as mensalidades nas referidas escolas. A grade curricular foi definida no artigo $2^{\circ}$ :

A mesma Escola será regida por hum Director, que ensinará. Primo: a ler e escrever pelo methodo Lancasteriano, cujos princípios theoricos e práticos explicará. Segundo: as quatro operações de Arithmetica, quebrados, decimaes e proporções. Tertio: noções geraes de Geometria theocrica e pratica. Quarto: Grammatica de Língua Nacional. Quinto: elementos de Geographia. Sexto: os princípios de Moral Christã, e da Religião do Estado (RIO DE JANEIRO, 1835).

A Escola Normal da Bahia, criada em 1836, só funcionou efetivamente em 1842, pois professores foram enviados à França para se formarem e não havia um estabelecimento para sediar a escola. Historiadores costumam imputar a demora no início de suas atividades à falta de condições de funcionamento e à influência de acontecimentos políticos da época. Ela teve sua criação impulsionada pelo Ato Adicional de 1834 e surgiu com a Lei n³7, de 14 de abril de 1836, que 
[...] estabelece: a estrutura curricular da escola, o método de ensino que deverá ser utilizado nas escolas de "Primeiras Letras"; a necessidade de enviar professores para a França, a fim de serem instruídos na Escola Normal de Paris; a utilização da teoria e da prática no método de Ensino Mútuo; o ordenado dos docentes; a total supervisão do Presidente da Província quanto ao local de funcionamento e a conduta de seus alunos; as condições de admissão de alunos e alunas, dentre elas a comprovação de bons antecedentes; a obrigatoriedade de os atuais professores e professoras de "Primeiras Letras" frequentarem a Escola Normal; a criação de uma sessão especial para as mulheres; e a indicação de que, num futuro próximo, fosse elaborado um regulamento que definisse o funcionamento dessa escola (LIMA, 2006, p.155).

A Escola Normal do Mato Grosso, no que se refere ao funcionamento definitivo, não foi muito diferente da escola normal baiana, vindo a funcionar apenas a partir de 1840, apesar de prevista na Lei $n^{\circ} 8$, de 5 de maio de 1837. Esta trouxe os fundamentos e as propostas para a formação de professores e previu no artigo $1^{\circ}$ o estabelecimento de uma Escola Normal na capital para instrução primária de primeiro grau (preparar professores para ensinar a ler, a escrever, as quatro operações aritméticas e princípios religiosos); e segundo grau (preparar os professores para ensinar a ler, a escrever, a aritmética até proporções, gramática da língua nacional e noções gerais dos deveres religiosos e morais) pelo método mais expedito e que melhor correspondesse a seus fins. Nos lugares em que já existissem escolas de $2^{\circ}$ grau poderiam ser criadas escolas para meninas com um currículo diferenciado, que incluísse deveres domésticos (artigo $3^{\circ}$ ). Para a criação da Escola Normal, o governo foi autorizado

[...] a contratar com um cidadão brasileiro a regência da cadeira pelo tempo que for conveniente, e com o vencimento de que se fará menção no título segundo além da indenização da viagem caso tenha lugar; e quando nenhum apareça com reconhecida aptidão, poderá contratar com quem vá instruir-se na Escola Normal da Província do Rio de Janeiro, e venha reger a cadeira, tomando em todo caso as necessárias cautelas para que não seja a Fazenda Pública lesada, ou a Província iludida - Artigo 6 (SÁ; SIQUEIRA, 2000, p.67). 
A aludida lei previu a suspensão da atividade dos professores das escolas particulares que não tivessem a instrução necessária. Caso mantivessem as atividades seriam multados inicialmente e posteriormente em dobro, sendo os responsáveis presos de quinze a sessenta dias. Os docentes poderiam requerer o exame do Governo antes de abrirem suas escolas para estarem devidamente regularizados (artigo 70). A lei também fixou o valor dos vencimentos, mas os professores do secundário ganhavam mais que os de primeiras letras e as mulheres o mesmo que estes (artigos 8, 9 e 10). Os professores de primeiras letras que tivessem mais de 40 alunos e os do secundário com mais de 50 receberiam no final do ano uma gratificação de quatro mil réis a mais por aluno excedente (art. 12). Os pais e alunos poderiam voluntariamente pagar gratificações aos professores, que seriam demitidos se ensinassem com mais zelo os alunos que pagassem (art. 13). Ainda estavam previstas gratificações além das citadas e um plano de aposentadoria.

Para serem admitidos nas escolas, os candidatos deveriam ter mais de 18 anos, ter bom comportamento comprovado por documento, passar no exame público e saber o método mais expedito. Dava-se preferência para professores brasileiros no lugar de estrangeiros. O critério de desempate entre brasileiros era ter frequentado a escola normal; mas quem fosse demitido duas vezes não poderia retornar à profissão e os títulos concedidos eram vitalícios, salvo casos estabelecidos em lei (artigos 18 a 22).

Assim como as outras escolas normais, a de São Paulo, criada pela Lei n³4, de 16 de março de 1846, sofreu várias alterações estruturais e curriculares, além de fechamentos e reaberturas. Poderiam ser professores os cidadãos maiores de idade, com bom procedimento (bons costumes comprovados por documento expedido pelo lugar onde moraram pelo menos três anos antes), conhecimento do currículo e instrução prática de ensino. Seriam providos por meio de um exame realizado perante o presidente da Província e uma comissão fixa de três membros, sendo que depois de aprovados cabia ao Governo julgar se era útil ou não o provimento (SÃO PAULO, 1846).

As políticas de formação docente das Províncias do Rio de Janeiro, Bahia, Mato Grosso e São Paulo foram elaboradas vinculadas aos propósitos da Lei das Escolas de Primeiras Letras de 1827. Por mais que alguns dispositivos esboçassem um pouco mais detalhadamente como seria a preparação dos professores, regulamentando questões além dos 
exames, do currículo, dos salários e de ensaios de um plano de carreira, grande parte deles criava ao mesmo tempo as escolas de primeiras letras e as escolas normais. Segundo esta legislação, o lugar que o professor ocupava na sociedade era servir unicamente a estas escolas.

\section{O modelo dos professores adjuntos e um balanço do período monárquico}

Com base no que foi visto até aqui, é possível afirmar que no período monárquico subsistiram no Brasil três modelos de formação: os exames e os concursos, a criação de escolas normais e o regime dos professores adjuntos, de inspiração austríaca e holandesa. As províncias buscaram métodos menos custosos para preparar os professores, optando por exames e concursos ao invés de uma formação mais longa e específica através das escolas.

\footnotetext{
Estes, limitados às matérias do ensino primário e aos "métodos principais de ensino", submetidos a uma política partidária de protecionismo e desprovidos de rigor, só puderam carrear para o magistério um pessoal de baixo nível e exíguas habilitações (TANURI, 2000, p.65).
}

O modelo dos professores adjuntos ou alunos-mestres foi ao mesmo tempo uma resposta ao fracasso das escolas normais e uma solução mais barata, já que os professores "[...] atuariam nas escolas como ajudantes do regente de classe, aperfeiçoando-se nas matérias e práticas de ensino. Por esse meio seriam preparados os novos professores, dispensando-se a instalação de Escolas Normais" (SAVIANI, 2009, p.145). Os adjuntos acompanhavam os professores mais hábeis, progredindo gradualmente no ensino até o ponto de poderem reger sozinhos as aulas. Aprendiam na prática por meio da observação e da experiência. $\mathrm{O}$ sistema de adjuntos "[...] consistia em empregar aprendizes como auxiliares de professores em exercício, de modo a prepará-los para o desempenho da profissão docente, de maneira estritamente prática, sem qualquer base teórica" (TANURI, 2000, p.65).

No Rio de Janeiro este sistema foi introduzido pelo Regulamento de 14 de dezembro de 1849, após o fechamento da Escola Normal de Niterói, que foi posteriormente reaberta. Os professores adjuntos foram introduzidos também na Corte pelo Decreto n 1.331-A, de 17 de feve- 
reiro de 1854, que estabeleceu os requisitos para exercício do magistério público, em que os candidatos deveriam provar maioridade legal, moralidade e capacidade profissional (art.12). As exigências legais e morais para o exercício do magistério mostravam-se ainda mais rigorosas que as leis anteriores, pois a prova de moralidade deveria ser dirigida ao Inspetor Geral de Instrução Primária e Secundária, contendo os registros de moradia dos últimos três anos, atestados dos respectivos párocos. Estavam impedidos de assumir o cargo de professor quem tivesse cometido determinados crimes ou sofrido penas e acusações judiciais (art.14).

As candidatas eram avaliadas quanto ao seu estado civil, devendo provar as situações com documentos legítimos. As solteiras só poderiam ser professoras se tivessem mais de 25 anos completos e se lecionassem na casa dos pais, quando de reconhecida conduta moral (art.16). Os exames (arts. 17, 18 e 19) se davam na forma oral e escrita para aferir acapacidade profissional dos candidatos, com matérias não só do respectivo ensino, mas também sobre o sistema prático e o método de ensino (BRASIL, 1854).

No geral, eram privilegiados candidatos com experiência anterior e graduados. A classe dos professores adjuntos era formada por alunos das escolas públicas, maiores de 12 anos, que apresentassem rendimento diferenciado nos exames anuais, bom procedimento e propensão para o magistério. Dava-se preferência para os filhos de professores que tivessem bem servido a sociedade por 10 anos e para alunos pobres (art.35). Estes professores permaneceriam nas escolas como ajudantes, se aperfeiçoariam nas matérias, nas práticas de ensino (art.38) e seriam examinados anualmente para verificar seu aproveitamento (art. 39). Depois de três anos, os que tivessem mais de 18 anos e cumprissem todos os requisitos e aptidões seriam nomeados professores públicos para ocuparem as cadeiras vagas (BRASIL, 1854).

Algumas discussões políticas impulsionadas pelo ideário republicano que anunciava transformações ideológicas e culturais viam a educação como essencial para o desenvolvimento econômico e social da nação. Já cogitavam a possibilidade da obrigatoriedade do ensino elementar e a ação do Governo Central para subsidiar o ensino primário e secundário. Cabe destacar que a tônica do período monárquico foi a desresponsabilização do Poder Central com a educação. O novo regime trouxe esperanças de que esse quadro se alteraria, o que de fato não ocorreu. 
Neste contexto, apesar das contestações e de progressos (SAVIANI, 2009), o modelo das escolas normais ganhou certo prestígio, sendo visto como uma forma de progredir na educação da população e na formação dos professores. Em suma, inicialmente, o lugar dos professores nas políticas educacionais de formação era bastante limitado, pois ainda não existia uma política de fato, ficando a formação relegada à força de trabalho para atender as escolas de primeiras letras; os professores eram formados na perspectiva de atuarem nestas escolas e atender a este projeto. Posteriormente, os professores que ainda não eram alvo de nenhum reconhecimento e valorização nesta tarefa ideológica e politicamente imposta passaram a lograr certo reconhecimento junto às "[...] escolas normais no desenvolvimento quantitativo e qualitativo do ensino primário" (TANURl, 2000, p.66).

Até 1890 , a tentativa de formação para o Magistério que teve mais expressividade foi a implantação das escolas normais. Contudo, estas trouxeram como resultado propostas insuficientes que não lograram êxito na preparação docente, aliadas a um arcabouço legal que não conseguiu se desligar da criação das escolas de primeiras letras nas províncias. Teve como principal resultado uma preocupação excessiva em formar professores teoricamente, trazendo um curso científico que formava docentes sem o necessário conhecimento e habilidade didático-pedagógica para atuarem nas escolas de instrução primária.

O fracasso das tentativas de formação pela escola normal se deu também pelo fato de que havia pouco interesse da população pela profissão de professor, devido aos salários nada atrativos, a imagem negativa sobre este ofício e porque a sociedade baseada na economia agrária e escravista da época não exigia nem tinha infraestrutura financeira e política para sustentar um modelo que demandava e fomentava a expansão escolar. Entretanto, não se pode negar que as escolas normais serviram para impulsionar a preocupação com a formação e qualificação docente.

Em um balanço do período (1835-1890) podem ser indicadas diversas limitações presentes também nas leis de criação destas escolas, que foram lentamente sendo superadas durante a República até a organização dos institutos de educação. Dentre estas limitações destacam-se o estabelecimento de critérios desiguais que inferiorizavam as mulheres em relações aos homens, como exames diferenciados para homens e mulheres, currículos pensados de acordo com o sexo; por 
muito tempo a presença de ambos os sexos foi vista como um fator de promiscuidade.

Podem ser observadas também questões pontuais, comuns ao Magistério, independentemente de ser exercido por homens ou muIheres, como predominância de um caráter disciplinador, salários baixíssimos, falta de estabelecimentos próprios, condições mínimas e estruturais nas escolas, casos em que professores deveriam pagar pelos seus estudos, baixa procura pelas escolas normais, trazendo como consequência a falta de professores nas próprias escolas normais e nas de instrução primária. Se as iniciativas de criação das escolas normais eram incipientes, o que dizer então da possibilidade de uma política pública nacional de formação de professores? Esta obviamente não existia, fruto do descaso do Poder Público com a educação e com a formação de professores para este nível de ensino (TANURI, 2000).

\section{A formação de professores após 1890}

A relativa estabilidade alcançada na criação e organização das escolas normais após 1870 , culminando no estabelecimento de um padrão formativo, ocorreu com a reforma educacional do Estado de São Paulo em 1890, iniciada quase no mesmo período da transição do Império para a República.

O rompimento com o regime monárquico se deu com a ação do movimento republicano, com os conflitos do Governo Imperial com a Igreja e devido ao processo abolicionista. Estas situações geraram descontentamento nos apoiadores do governo, como a maioria dos senhores de escravos, que passaram a apoiar a causa republicana; os representantes da Igreja, insatisfeitos com sua submissão ao Estado; e os militares, que não aceitavam o pouco espaço de intervenção na vida pública. A oposição de tantos setores da sociedade à Monarquia tornou possível o golpe político que instaurou a República no Brasil.

Com o fim da Monarquia, as elites continuaram no poder, e até 1930 o país foi governado ora por militares e ora por membros da oligarquia rural, sem participação das camadas populares. Isto significou avanços modestos para a educação, já que os líderes do país estavam preocupados em garantir seus interesses econômicos e privilegiar as elites. No ínício da República o Brasil padecia com o analfabetismo da maioria da população (cerca de $85 \%$ ) e com a precariedade do investimento escolar. 
Com a Constituição da República dos Estados Unidos do Brasil de 1891 a descentralização foi mantida, permanecendo a escola primária e a normal sob responsabilidade das províncias, transformadas em estados. O Governo Central era responsável pelo ensino secundário e superior, todavia não exclusivamente. Os estados promoveram reformas nas suas escolas. Entretanto,

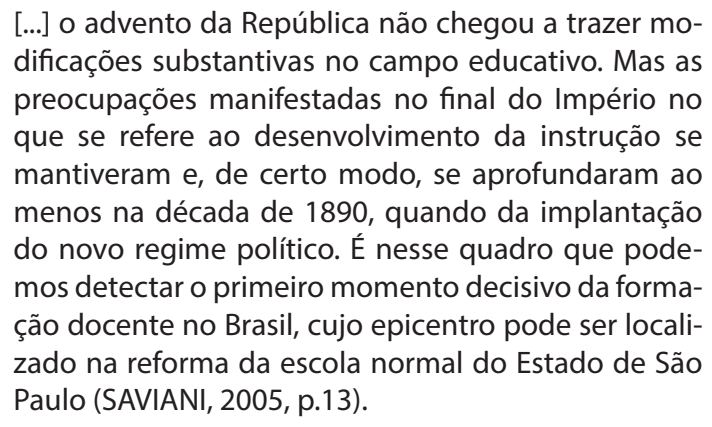

Cabe destacar que São Paulo teve um papel de destaque no movimento republicano e nessa época já se consolidava como uma das províncias mais importantes para a economia do país, com a cafeicultura. Por isso, com a República, passa a ocupar o centro do poder político, compartilhado com Minas Gerais, a partir de 1894 até 1930. Tal posição ampliou as demandas da população por educação, a partir dos interesses políticos das elites locais.

A Escola Normal de São Paulo atendia só alunos do sexo masculino, que no futuro poderiam se tornar professores de instrução primária. O currículo estava subordinado ao conteúdo a ser ensinado nas escolas primárias, porém omitia os estudos de História, Geografia, Ciências e era essencialmente teórico. As condições de funcionamento eram deficientes e a formação para o sexo feminino, mesmo que regulamentada por lei, não aconteceu. Esta escola foi marcada pelo desprestígio do Poder Público, pouquíssima procura por matrículas e várias críticas. Entre o fechamento, a reabertura e os problemas recorrentes foi forjado um cenário que contribuiu para a reforma da Escola Normal por meio do Decreto n²7, de 12 de março de 1890.

Deste modo, os movimentos paulistas em torno da preocupação, tanto pela instrução pública, como pela preparação dos professores, ganharam certa densidade, não vista em anos de ensaios sem resultado na criação e normatização do modelo das escolas normais; tornando-se 
um padrão para os outros estados. A proposta de reforma partiu de um diagnóstico da situação da formação na época, visto que a escola não satisfazia as exigências de preparação dos candidatos ao magistério, devido à insuficiência da grade curricular e a um plano de formação que tinha o caráter teórico em detrimento da preparação prática.

O Decreto 27/1890 trouxe inovações e perspectivas de avanço: o ensino normal seria gratuito e para ambos os sexos (art. 2), com um curso de 3 anos (art. 3); professores e professoras nacionais e estrangeiros seriam contratados pelo governador (art. 5); contudo, a diferenciação de currículos para homens e mulheres foi mantida. Os candidatos deveriam provar perante o diretor da escola serem maiores de 15 anos; se mulheres maiores de 17; se homens, terem sidos aprovados nos exames de Português, Francês, Geografia, Caligrafia (art. $8^{\circ}$ ) e apresentar documentos que comprovassem proficiência, moralidade e exercício proveitoso da profissão (art.10). O quadro de funcionários da escola normal estava mais bem desenhado, composto por diretores, professores efetivos e contratados, preparadores de educação física, secretários, bibliotecários, entre outros (art.11). As primeiras cadeiras seriam providas por livre nomeação do governador, os concursos para professores seriam por votação nominal e deveriam especificar os motivos de preferência na classificação dos candidatos (art. 16). Professores contratados deveriam somar cinco anos de exercício para estarem aptos a serem nomeados efetivos (art. 17).

Outra mudança trazida pelo decreto, que significou uma resposta ao problema da formação essencialmente teórica e tornou a Escola Normal de São Paulo referência na preparação prática dos professores, chegando a receber candidatos de outras escolas do Brasil, foi a criação das escolas-modelo definida do artigo 20 ao 30. Foram criadas duas escolas-modelo, uma para cada sexo, anexas à Escola Normal, destinadas a alunos de $3^{\circ}$ ano para exercerem a prática do professorado com um programa de ensino dividido em três seções correspondentes aos três graus. No programa do curso feminino eram acrescentadas disciplinas sobre economia doméstica, costura e trabalhos manuais. As lições deveriam ser mais empíricas do que teóricas, visando o desenvolvimento gradual dos alunos.

A reforma de São Paulo teve dois fios condutores, como explica Saviani (2009), o enriquecimento do currículo e a ênfase nos exercícios práticos, que teve como decorrência a criação da escola-modelo. Os reformadores entendiam que sem uma deliberada e sistemática prepara- 
ção pedagógico-didática não se estava formando de fato professores. A escola-modelo ganhou importância, tornou-se referência pedagógica para todo o Estado de São Paulo e para outros estados.

[...] a reforma ali implantada se tornou referência para outros Estados do país. Estes enviavam seus educadores para observar e estagiar em São Paulo ou recebiam "missões" de professores paulistas na condição de reformadores, como ocorreu em Mato Grosso, Espírito Santo, Santa Catarina, Sergipe, Alagoas, Ceará, além de outros, ao longo dos primeiros 30 anos do regime republicano (SAVIANI, 2005, p.15).

Outras legislações deram continuidade ao movimento reformador paulista intensificando e modificando algumas propostas. A Lei n88, de 8 de setembro de 1892, que reformou a instrução pública de São Paulo, foi a primeira política educacional brasileira com uma seção específica intitulada "Formação de Professores" e que criou o primeiro curso superior de formação, além de criar um ensino primário dividido em dois cursos, preliminar e complementar. Os professores do ensino primário eram formados em quatro escolas normais primárias, os professores destas escolas e dos ginásios eram formados na escola normal da capital, através de um curso superior (art.23). Os professores das escolas normais primárias montavam o programa da disciplina que lecionariam no início do ano letivo para aprovação (art. 26).

A grade curricular e os requisitos para ingresso nestas escolas não variaram muito em relação às políticas já praticadas. No final do $3^{\circ}$ ano de curso, os alunos já estavam aptos para dar aulas nas escolas preliminares e complementares, desde que praticassem obrigatoriamente por seis meses nas escolas-modelo (arts. 28 e 29). O curso superior era de dois anos, com duas seções, uma científica e uma literária. Para ingressarem na seção literária da escola da capital, além de dominarem as matérias das escolas normais primárias, os alunos deveriam estar habilitados em grego e latim (art. 31). Aos poucos, o concurso se tornava uma etapa obrigatória para o cargo de professores e outros cargos educacionais eram definidos. Os professores do Estado foram classificados em sete categorias: adjuntos primários, professores primários, adjuntos de escolas complementares, professores de escolas complementares, professores de escolas normais primárias, professores de curso superior e professores de ginásios (art.38). 
A Lei nº169, de 7 de agosto de 1893, mudou de três para quatro anos o curso normal, determinou o fim da distinção entre curso preliminar e complementar, o que não se efetivou na prática, entre outras alterações. Com a Lei n³74, de 3 de setembro de 1895, foi acrescentado um ano de prática de ensino nas escolas-modelo (arts. 1 e 3). Uma das principais inovações do Decreto n`2.025, de 29 de março de 1911, foi a transformação das escolas complementares, com exceção da escola da capital, em escolas normais primárias.

Pela redação do referido decreto, o ensino normal era gratuito e facultado a ambos os sexos separadamente (art.3), só que estava prevista uma taxa de matrícula (art.5). Para realizar a inscrição nas escolas normais primárias os candidatos não poderiam ter nenhum defeito físico ou psíquico que fosse incompatível com o magistério e, no caso das candidatas, deveriam comprovar serem solteiras (art. 23)

Transformadas as escolas complementares em escolas normais primárias (1911), e denominadas as de padrão mais elevado de "normais secundárias", consolidou-se um dualismo que, embora adotado em outras unidades da federação, já em 1920 (Lei n. 175, de 8/12/1920) seria abolido em São Paulo, com a unificação de todas as escolas normais, pelo padrão das mais elevadas (TANURI, 2000, p.69).

Embora a legislação da reforma paulista permanecesse até 1920, como esclarece Saviani (2004), o curso superior de formação não foi implantado e algumas mudanças não foram efetivadas. Diante dos pequenos avanços conquistados com muitos projetos dos líderes políticos, o movimento de consolidação do modelo das escolas normais

"[...] não se traduziu em avanços muito significativos,
trazendo ainda a marca da força do padrão até então
dominante, centrado na preocupação com o domínio
dos conhecimentos a serem transmitidos" (SAVIANI,
2009, p.145).

A constatação de Saviani não causa espécie, visto ser esta uma característica histórica da educação brasileira, a qual infelizmente perdurará por longo tempo, apesar dos esforços renovadores nas décadas seguintes. 


\section{O movimento renovador da década de 1920}

O impulso renovador da reforma paulista aos poucos atingiu outros estados, de forma que as críticas ao modelo de ensino e a constituição das escolas deixava de ser só uma matéria dos discursos para ganhar mais consistência e se transformar em ações, dando continuidade ao movimento de consolidação da formação de professores ainda embasado principalmente pelas escolas normais. As críticas contrárias ao ensino ministrado nas escolas normais se voltaram não só para o hibridismo do ensino normal e para a ênfase na preparação prática em detrimento do conhecimento teórico, mas também para a necessidade de uma formação específica de profissionalização do professor que corrigisse as antigas insuficiências.

A década de 1920, no Brasil, foi marcada por grande efervescência política e anseios renovadores no campo da educação, arte e cultura, sendo os eventos mais marcantes a Semana de Arte Moderna e a Revolta dos Tenentes, ambos em 1922.

Foi neste momento que "[...] desencadeou-se um amplo processo de organização do campo educacional impulsionado pelo movimento renovador" (SAVIANI, 2005, p.15-16), que ganhou força nos dois ciclos de reformas promovidas na década de 20 . O primeiro até 1925 , caracterizado pela fixação das normas já constituídas, contou com as iniciativas no Ceará, no Paraná, no Rio Grande do Norte e na Bahia. O segundo ciclo, interrompido com a crise de 1929, de incorporação mais metódica das ideias renovadoras, foi composto por reformas em Minas Gerais, no Distrito Federal e em Pernambuco.

Estas iniciativas buscaram reformar o ensino estadual que vivia uma situação de precariedade com professores despreparados, grande número de analfabetos e falta de escolas. Estas reformas do ensino primário e normal forneceram elementos para uma revisão crítica dos padrões de escola normais existentes (TANURI, 2000).

Assim como ocorreu no campo cultural, com o Modernismo influenciando a arte e a literatura, o ideário escolanovista esteve presente no pensamento dos intelectuais da educação que na época estiveram à frente das reformas educacionais em curso em diversos estados da federação. As aludidas reformas representaram avanços no campo educacional, trazendo iniciativas que foram sendo incorporadas ao modelo de escola normal brasileira e serviram para consolidá-lo, como 
“ [...] a criação ou a ampliação dos estudos complementares, preparatórios ao normal, [...] e, em alguns casos, a divisão do curso normal em dois ciclos: um geral ou propedêutico e outro especial ou profissional" (TANURI, 2000, p.70).

Foram introduzidas novas disciplinas nos currículos, normas didático-pedagógicas e houve a instalação de uma escola de aperfeiçoamento, destinada aos professores já em exercício. Este movimento de transformação permitiu de um lado a expansão das escolas normais menos elevadas; e do outro a afirmação do papel do ensino normal na preparação dos professores para o ensino primário, uma vinculação presente desde as primeiras escolas normais. Também foram estabelecidas escolas normais privadas com intuito de suprir a falta de escolas oficiais na maioria dos estados. É importante ressaltar que elas existiam desde o Império, respaldadas pela liberdade de ensino assegurada na Constituição de 1891 e que em alguns casos representavam a maioria de estabelecimentos para este fim, diante de uma pequena proporção de escolas normais públicas.

Por volta do final dos anos 20, as escolas normais já haviam ampliado bastante a duração e o nível de seus estudos, possibilitando, via de regra, articulação com o curso secundário e alargando a formação profissional propriamente dita, graças à introdução de disciplinas, princípios e práticas inspirados no escolanovismo, e a atenção dada às escolas-modelo ou escolas de aplicação anexas (TANURI, 2000, p.72).

A pedagogia renovadora foi formulada partindo da crítica à pedagogia tradicional e visando superar a visão da escola como instituição centrada no professor incumbido de transmitir os conhecimentos e o acervo cultural aos alunos. Este sistema exigia um professor razoavelmente preparado para aplicar os exercícios aos alunos em uma organização disciplinar para seguirem as lições. A questão pedagógica deslocou-se do

[...] aspecto lógico para o psicológico; dos conteúdos cognitivos para os métodos ou processos pedagógicos do professor para o aluno; do esforço para o interesse; da disciplina para a espontaneidade; do diretivismo para o não-diretivismo; da quantidade para a qualidade; de uma pedagogia de inspiração filosófica 
centrada na ciência da lógica para uma pedagogia de inspiração experimental centrada principalmente nas contribuições da biologia e da psicologia (SAVIANI, 1999, p.9).

A escola proposta pela pedagogia nova não alcançou êxito uma vez que exigia uma reformulação da relação professor-aluno, do processo de ensino-aprendizagem e do panorama institucional e organizacional que não foi possível, sem contar que a escola renovada era bem mais custosa do que a tradicional. No fim, o escolanovismo inspirou raros núcleos experimentais muito bem equipados e restritos para a elite e foi difundido entre educadores, gerando consequências nas redes escolares oficiais.

\section{Considerações Finais}

A formação de professores no período investigado variou em graus de desimportância no campo político-educacional. Tiveram destaque iniciativas ligadas a experiências informais e sistemas de indicação, métodos de escolha teoricamente mais estruturados através de conselhos e comissões, ligados a uma fase em que predominaram exames e concursos de admissão; a instalação das escolas normais públicas e privadas e o regime dos professores adjuntos. Estas iniciativas caracterizam-se pela vinculação entre criação das escolas elementares e de instituições responsáveis pela formação do professor para trabalhar nestas escolas. Caracterizaram-se também pela relação entre a qualidade da preparação, a sistematização e a organização dos modelos e estabelecimentos, ou seja, quanto menos estruturada e consolidada era a proposta, mais se repetia o quadro de insuficiência na formação.

A fase anterior a 1930 foi caracterizada por Saviani (2011) como um período de descontinuidade, embora sem rupturas, com movimentos de mudanças e reformas parciais, iniciativas que não tinham fundamento nem consistência para vigorar, nem se desvencilhavam dos velhos entraves e modelos. Estas interrupções e reviravoltas se devem principalmente às escolas normais, que na sua história acumulam fechamentos e reaberturas.

Muitas das críticas dirigidas às mudanças desencadeadas permanecem relevantes, pois professores para atuar no ensino primário ainda são formados nas escolas normais. A formação de professores nos 
cursos de pedagogia, criados em 1939, trouxe inovações, mas seus currículos conservam boa parte das antigas disciplinas das escolas normais, apenas adotando nomes mais modernos.

Em suma, a formação docente via escolas normais para preparar os professores primários permaneceu no século XX com pequenos avanços através de novas legislações, sem alterar o cenário de interrupções e retrocessos. Nos dias atuais, as escolas normais representam um legado com pouca expressividade, mas com um papel ainda relevante diante do fracasso da meta nacional de formar professores em nível superior, introduzida pela Lei de Diretrizes e Bases da Educação Nacional no. 9394/96, que não consegue se consolidar por força de pressões de legisladores e de governantes de estados e municípios, assentadas na perspectiva de aumento significativo dos custos educacionais. Mas isso já é assunto para outro artigo.

\section{Referências}

BRASIL. Lei de 15 de outubro de 1827. Manda crear escolas de primeiras letras em todas as cidades, villas e logares mais populosos do Imperio. Disponível em:<<http://www2.camara.leg.br/atividadelegislativa/legislacao/publicacoes/doimperio/colecao2.html>. Acesso em: 10 abr. 2016.

.Municipio da Côrte. Decreto n¹.331-A, de 17 de fevereiro de 1854. Approva o Regulamento para a reforma do ensino primario e secundario do Municipio da Côrte. Rio de Janeiro: Secretario d'Estado dos Negocios do Imperio, 1854. Disponível em:<http:// www2.camara.leg.br/legin/fed/decret/1824-1899/decreto-1331a-17-fevereiro-1854-590146-publicacaooriginal-115292-pe.html>. Acesso em: 10 abr. 2016.

LIMA, M. M. L. Ingresso das mulheres no magistério da Bahia: o resgate de uma história. Tese (Doutorado em Educação) - Faculdade de Educação, Universidade Federal da Bahia, Salvador, 2006, 181 p.

MATO GROSSO. Lei n8, de 5 de maio de 1837. Dá regulamento a instrução pública na Província de Mato Grosso. In: SÁ, N. P.; SIQUEIRA, E. M. (Org.). Leis e regulamentos da instrução púbica do império em Mato Grosso. Campinas: Autores Associados; SBHE, 2000, p.11-18. 
RIO DE JANEIRO. Decreto nº10, de 10 de abril de 1835. Dispõe sobre a organização do ensino normal e estabelece as normas de ingresso nesta modalidade de ensino. Disponível em:<https://repositorio. ufsc.br/xmlui/bitstream/handle/123456789/99970/1835_10_abril_Ato _n\%C2\%BA10_Cria_Escola_Normal.pdf? sequence $=1$ \&isAllowed $=y>$. Acesso em: 02 jan. 2016.

SÁ, N. P.; SIQUEIRA, E. M. Leis e regulamentos da instrução pública do império em Mato Grosso. Campinas: Autores Associados, 2000.

SÃO PAULO. Lei n 34, de 16 de março de 1846. Dá nova organização às escolas de instrução primária e cria uma escola normal. Disponível em:<http://www.al.sp.gov.br/repositorio/legislacao/lei/1846/lei-3416.03.1846.html >. Acesso em: 02 jan. 2016.

. Decreto $n^{\circ} 27$, de 12 de março de 1890.Reforma a Escola Normal e converte em Escolas Modelos as Escolas annexas. Disponível em:<http://www.al.sp.gov.br/repositorio/legislacao/decreto/1890/ decreto-27-12.03.1890.html>. Acesso em: 10 abr. 2016.

. Lei no88, de 8 de setembro de 1892. Reforma a instrucção pública do Estado.Disponível em:<http://www.al.sp.gov.br/repositorio/ legislacao/lei/1892/lei-88-08.09.1892.html>. Acesso em: 10 fev. 2016.

. Lei n¹69, de 7 de agosto de 1893.Addila diversas disposições á lei $\mathbf{n . 8 8}$, de 8 de Setembro de 1892. Disponível em:<http://www. al.sp.gov.br/repositorio/legislacao/lei/1893/lei-169-07.08.1893.html>. Acesso em: 10 fev. 2016.

. Decreto n`2.025, de 29 de março de 1911. Converte as actuaes Escolas Complementares do Estado em Escolas Normaes Primarias e dá-Ihes regulamento. Disponível em:<http://www.al.sp.gov.br/ repositorio/legislacao/decreto/1911/decreto-2025-29.03.1911.html>. Acesso em: 10 fev. 2016.

SAVIANI, D. Escola e democracia. Campinas: Autores Associados, 1999.

. A escola pública brasileira no longo século XX (1890-2001). In: III Congresso Brasileiro de História da Educação, 3, 2004, Curitiba.Anais... Curitiba: SBHE, 2004, p.1-11, CD-ROM. Disponível em:<http://sbhe. org.br/novo/congressos/cbhe3/Documentos/Coord/Eixo3/483.pdf>. Acesso em: 02 jan. 2016. 
. História da formação docente no Brasil: três momentos decisivos.

Educação, Santa Maria, v.30, n.2, p.11-26, 2005. Disponível em:<http:// periodicos.ufsm.br/reveducacao/article/view/3735/2139>. Acesso em: 02 jan. 2016.

. Formação de professores: aspectos históricos e teóricos do problema no contexto brasileiro. Revista Brasileira de Educação, Rio de Janeiro, vol.14, n. 40, p.143-155, abr. 2009. Disponível em:<www. scielo.br/pdf/rbedu/v14n40/v14n40a12.pdf>. Acesso em: 12 out. 2015.

. Formação de professores no Brasil: dilemas e perspectivas. Poíesis Pedagógica, Catalão, v. 9, n. 1, p.7-19, set. 2011. Disponível em:<https://www.revistas.ufg.br/poiesis/article/view/15667>. Acesso em: 12 out. 2015.

SCHAFFRATH, M. A. S. Escola Normal: o projeto das elites brasileiras para a formação de professores. In: I Encontro do Grupo Interdisciplinar de Pesquisa em Artes da FAP, 1, 2008, Curitiba.Anais... Curitiba: Faculdade de Artes do Paraná, 2008, p.142-152, CD-ROM. Disponível em: <http:// www.fap.pr.gov.br/arquivos/File/Arquivos2009/Extensao/I_encontro_ inter_artes/20_Marlete_Schaffrath.pdf>. Acesso em: 02 jan. 2016.

TANURI, L. M. História da formação de professores.Revista Brasileira de Educação, Campinas, s/v, n.14, p. 61-88, maio/ago. 2000. Disponível em:<http://www.scielo.br/pdf/rbedu/n14/n14a05>. Acesso em: 22 jul. 2016.

Recebido em junho/2017

Aceito em setembro/2017 